\title{
SOLID FILM LUBRICANTS AND THERMAL CONTROL COATINGS FLOWN ABOARD THE EOIM-3 MDA SUB-EXPERIMENT
}

\author{
Taylor J. Murphy*, Kaia E. David*, and Hank W. Babel** \\ McDonnell Douglas Aerospace \\ Huntington Beach, CA 92647 \\ Phone: (714) 896-3311/Fax: (714) 896-5034
}

\begin{abstract}
Additional experimental data were desired to support the selection of candidate thermal control coatings and solid film lubricants for the McDonnell Douglas Aerospace (MDA) Space Station hardware. The third Evaluation of Oxygen Interactions With Materials Mission (EOIM-3) flight experiment presented an opportunity to study the effects of the low Earth orbit environment on thermal control coatings and solid film lubricants. MDA provided five solid film lubricants and two anodic thermal control coatings for EOIM-3. The lubricant sample set consisted of three solid film lubricants with organic binders, one solid film lubricant with an inorganic binder, and one solid film lubricant with no binder. The anodize coating sample set consisted of undyed sulfuric acid anodize and cobalt sulfide dyed sulfuric acid anodize, each on two different substrate aluminum alloys. The organic and inorganic binders in the solid film lubricants experienced erosion, and the lubricating pigments experienced oxidation. MDA is continuing to assess the effect of exposure to the low Earth orbit environment on the life and friction properties of the lubricants. Results to date support the design practice of shielding solid film lubricants from the low Earth orbit environment. Post-flight optical property analysis of the anodized specimens indicated that there were limited contamination effects and some atomic oxygen and ultraviolet radiation effects. These effects appeared to be within the values predicted by simulated ground testing and analysis of these materials, and they were different for each coating and substrate.
\end{abstract}

\section{INTRODUCTION}

There exists a fair body of data on the effects of low Earth orbit (LEO) environment on general classes of materials and some simulated LEO environment tests on solid film lubricants and thermal control coatings, but there are little data in the literature on LEO exposure of dry film lubricants and no data for the anodic thermal control coating processes developed by MDA for the international Space Station. In the case of lubricants, the unknown parameter of LEO effects forces LEO-exposed hardware to be conservatively designed, incorporating protective shielding, assuming a higher friction value than the lubricant typically provides, and reducing the predicted service life of the hardware. Hardware with thermal control coatings are similarly affected by the lack of data on LEO effects. Designers must incorporate large uncertainties in the end of life (EOL) optical properties, which control the final temperature of the hardware. The end result of accommodating the unknown effects is consumption of space, power, and weight allocations, which are precious resources on spacecraft. Developing a better understanding of LEO effects

*Engineer/Scientist, Materials and Processes; Member, AIAA

**Senior Manager, Materials and Processes 
on solid film lubricants and anodic thermal control coatings would result in the efficient consumption of these allocations.

\section{LEO Effects on Solid Film Lubricants}

Most solid film lubricants consist of an organic binder and a lubricating pigment, such as molybdenum disulfide $\left(\mathrm{MoS}_{2}\right)$. The only data available for use in predicting LEO environmental effects on solid film lubricants are (1) the observed effects of LEO environment on materials similar to the organic binder; and (2) the effects of a simulated LEO environment on sputtered $\mathrm{MoS}_{2}$.

Based on available data, LEO effects on organic binders are expected to be erosion due to the synergistic effects of $\mathrm{AO}$ and ultraviolet (UV) radiation. In general, organic materials that do not contain fluorine or silicone exhibit AO reaction efficiencies on the order of $2.5-3.010^{-24} \mathrm{~cm}^{3} /$ atom AO. ${ }^{1} \mathrm{AO}$ flux for the Space Station is estimated to average $5 \times 10^{21}$ atoms $/ \mathrm{cm}^{2}-\mathrm{yr}$, yielding erosion rates on the order of 0.013 to $0.015 \mathrm{~cm} / \mathrm{yr}(0.0005$ to $0.0006 \mathrm{in} . / \mathrm{yr})$ for organic materials oriented normal to the Space Station velocity vector. The applied thickness of most solid film lubricants is between 0.013 and $0.026 \mathrm{~cm}(0.005$ and $0.010 \mathrm{in}$.).

The effects of $\mathrm{AO}$ on the $\mathrm{MoS}_{2}$ pigments may be estimated using data from simulated LEO environment tests. It was found that sputtered $\mathrm{MoS}_{2}$ exhibited the following effects when exposed to an $\mathrm{AO}$ fluence of $5 \times 10^{24}$ atoms $/ \mathrm{cm}^{2}$ with $1.5 \mathrm{eV}$ energy: 2

1. Creation of $\mathrm{MoO}_{3}$ and $\mathrm{MoO}_{2}$, in estimated amounts of $45 \%$ and $15 \%$, respectively, from the $\mathrm{MoS}_{2}$ present at the surface.

2. Creation of a layer consisting of sulfides and oxides, approximately $90 \AA$ thick, which inhibits adsorption of $\mathrm{AO}$.

3. Creation of $\mathrm{SO}_{2}$, which degasses from the specimen.

4. Relatively high coefficients of friction (0.2), until the protective layer is worn off and a fresh $\mathrm{MoS}_{2}$ surface is exposed (within 10 cycles).

Estimates of the effects of LEO environment on a solid film lubricant's performance based on the above information are rough at best. MDA's objectives in this experiment were (1) to determine the chemical and physical changes of several different types of solid film lubricants exposed to LEO and (2) to assess the effect of exposure on lubrication properties.

\section{Anodic Thermal Control Coatings}

As has been discussed in previous papers, anodic coatings were selected for the MDA Space Station aluminum hardware over organic based thermal control coatings because of their demonstrated resistance to LEO environmental effects. ${ }^{3}$ Sulfuric acid anodizing (SAA) was selected in part because of the ease of 
controlling the optical properties during manufacture of large hardware. ${ }^{4}$ Some SAA thermal control coatings had been shown to exhibit minimal increases in solar absorptance $\left(\alpha_{S}\right)$ on exposure to groundbased UV radiation. 5 Other SAA thermal control coatings exhibited severe degradation on exposure to simulated UV radiation. ${ }^{6}$ Low absorptance SAA thermal control coatings have been reported in the literature to degrade between 0.1 and 0.2 on UV exposure. ${ }^{6}$ In the mid-1960s, LaRC tested cobalt-sulfide dyed SAA coatings with very high absorptances. This coating showed excellent absorptance retention after UV exposure. ${ }^{7}$ Intermediate-absorptance coatings in the range of 0.4 to 0.7 have received little attention. These are the coatings planned for use on the Space Station program.

There are numerous factors that influence anodic coating optical property degradation in the LEO environment. Processing parameters such as the anodizing temperature, time, current density, electrolyte concentration, and sealing medium can affect degradation from UV radiation. Alloy, temper, and some processing parameters can affect the retention of dyes in the pore structure on exposure to AO. Coating thickness can affect the amount of cracking on exposure to thermal cycling and meteoroid and orbital debris impacts. Contamination that exists around a spacecraft can affect the optical properties of exposed surfaces, but has also been shown to affect some types of coatings more than others. ${ }^{4}$ This contamination can also contribute to an increase in absorptance because of the interaction with the natural environments.

New coating processes and variants are generally evaluated individually for AO and UV effects. However, to determine their acceptability for LEO, combined $\mathrm{AO}, \mathrm{UV}$, and contamination environmental testing for each variant is recommended. Flight testing is an important part of this evaluation. MDA flew two non-dyed (clear) SAA coatings and two cobalt sulfide (CoS) dyed (black) SAA coatings on the EOIM-3 mission as a part of a larger set of ground and flight tests in a program to verify the acceptability of these coatings for use on Space Station hardware.

\section{SAMPLE DESCRIPTION}

All MDA EOIM-3 samples were vacuum-baked prior to installation into sample carrier trays.

\section{Lubricant Samples}

Five different solid film lubricants were studied in this test. The sample set is described in Table 1 . Three were $\mathrm{MoS}_{2}$-type lubricants with phenolic, polyimide, and inorganic binders. One other consisted of niobium diselenide ( $\left.\mathrm{NbSe}_{2}\right)$ and a phenolic binder, and the last one utilized tungsten disulfide (WS2) with no binder. Each lubricant was applied by the lubricant vendors on aluminum 6061-T6 substrates. During flight, some of the lubricant samples had a mesh screen placed over them, as noted in the table.

\section{Anodic Samples}

The anodic thermal control coating samples and pre-flight data are listed in Table 2 . Aluminum sheet and plate material were cut into 0.875 -in. diameter discs prior to anodizing. The anodizing for all the samples was performed in the Chemistry Laboratory pilot process line at the MDA Huntington Beach 
Table 1. MDA Lubricant Sample Set

\begin{tabular}{|c|c|c|c|c|c|}
\hline \multirow[b]{2}{*}{ Lubricant } & \multirow[b]{2}{*}{$\begin{array}{l}\text { Lubricating } \\
\text { pigment }\end{array}$} & \multirow[b]{2}{*}{ Binder and cure } & \multicolumn{3}{|c|}{ Sample size } \\
\hline & & & $\begin{array}{l}\text { Pass. } \\
\text { tray }\end{array}$ & $\begin{array}{l}60^{\circ} \mathrm{C} \\
\text { tray }\end{array}$ & $120^{\circ} \mathrm{C}$ tray \\
\hline Lubricant 1 & $\begin{array}{l}\mathrm{MoS}_{2} \text { and graphite } \\
\text { (proprietary) }\end{array}$ & $\begin{array}{l}\text { Phosphoric acid based } \\
\text { (proprietary) } \\
\text { Cure } 204^{\circ} \mathrm{C}\left(400^{\circ} \mathrm{F}\right)\end{array}$ & 1 in. (S) & $1 \mathrm{in.}$ & 1 in. \\
\hline Lubricant 2 & $\mathrm{MoS}_{2} / \mathrm{Sb}_{2} \mathrm{O}_{3}$ & $\begin{array}{l}\text { Polyimide } \\
\text { Cure } 0.5 \mathrm{hr} \text { at } 149^{\circ} \mathrm{C}\left(300^{\circ} \mathrm{F}\right) \text {, } \\
\text { then } 1 \mathrm{hr} \text { at } 302^{\circ} \mathrm{C}\left(575^{\circ} \mathrm{F}\right)\end{array}$ & & & 0.5 in. (S) \\
\hline Lubricant 3 & $\begin{array}{l}\text { Niobium Diselenide } \\
\left(\mathrm{NbSe}_{2}\right)\end{array}$ & $\begin{array}{l}\text { Phenolic } \\
\text { Air Dry Cure }\end{array}$ & 1 in. & $1 \mathrm{in.}$ & 1 in. \\
\hline Lubricant 4 & $\mathrm{MoS}_{2}$ & $\begin{array}{l}\text { Modified phenolic } \\
\text { Cure } 1 \mathrm{hr} \text { at } 191^{\circ} \mathrm{C}\left(375^{\circ} \mathrm{F}\right)\end{array}$ & 1 in. & 1 in. & 1 in. \\
\hline Lubricant 5 & $\mathrm{WS}_{2}$ & - & 1 in. $(S)$ & 1 in. & 1 in. \\
\hline
\end{tabular}

Note: The symbol $(S)$ denotes samples flown with a mesh screen cover.

Table 2. Pre-Flight Optical Properties of the MDA Anodic Samples, $200^{\circ} \mathrm{C}$ Trays

\begin{tabular}{l|l|c|c|c|c}
\hline Coating & Substrate & $\begin{array}{c}\text { Coating } \\
\text { thickness } \\
\text { (mils) }\end{array}$ & $\begin{array}{c}\text { Absorptance } \\
\text { (Lambda-9) }\end{array}$ & $\begin{array}{c}\text { Absorptance } \\
\text { (MS-251) }\end{array}$ & Emittance (DB-100) \\
\hline Clear SAA & $2219-\mathrm{T} 851$ & 0.6 & 0.47 & 0.49 & 0.86 \\
\hline Clear SAA & $7075-\mathrm{T} 73$ & 1.1 & 0.45 & 0.45 & 0.88 \\
\hline CoS Dyed SAA & $6061-\mathrm{T} 6$ & 1.0 & $0.79^{*}$ & 0.79 & 0.86 \\
\hline CoS Dyed SAA & $7075-\mathrm{T} 73$ & 0.5 & $0.84^{*}$ & 0.82 & 0.82 \\
\hline
\end{tabular}

* Not measured-typical values shown

facility. The temperature-controlled 11-liter lead tank was used as the cathode. The anodizing procedure for the anodized samples is shown in Table 3.

\section{TEST DESCRIPTION}

The EOIM-3 Mission flew on the 31 July 1992 STS-46 flight, which orbited at an altitude of $230 \mathrm{~km}$ (124 nautical miles) and an inclination of $28.5 \mathrm{deg}$ from the equator. The experiment was deployed on 6 August 1992 and was exposed for 42 hours. The exposure environment is described as follows: ${ }^{8}$

AO fluence $=2.3 \times 10^{20}$ atom $/ \mathrm{cm}^{2}$ (annualized flux $=5 \times 10^{22}$ atom $/ \mathrm{cm}^{2}$-yr).

UV exposure $=25$ equivalent sun hours.

Passive tray temperature $=10$ to $50^{\circ} \mathrm{C}\left(50\right.$ to $\left.120^{\circ} \mathrm{F}\right)$, with excursions to $80^{\circ} \mathrm{C}\left(176^{\circ} \mathrm{F}\right)$ prior to deployment.

MDA lubricant samples were located on the passive trays and on the $60^{\circ} \mathrm{C}\left(140^{\circ} \mathrm{F}\right)$ and $120^{\circ} \mathrm{C}\left(248^{\circ} \mathrm{F}\right)$ trays, as indicated in Table 1. All MDA anodic thermal control samples were located on $200^{\circ} \mathrm{C}\left(392^{\circ} \mathrm{F}\right)$ trays. After de-integration from the flight hardware, the samples were placed in individual nonmetallic sample holders. 
Table 3. Anodizing Procedure

\begin{tabular}{l|l|c}
\hline \multicolumn{1}{c|}{ Anodizing parameters } & $\begin{array}{c}\text { Non-dyed sulfuric } \\
\text { acid anodize }\end{array}$ & $\begin{array}{c}\text { Cobalt sulfide dyed sulfuric } \\
\text { acid anodize }\end{array}$ \\
\hline Pre-treatment: & Yes & Yes \\
Solvent wipe with 1,1,1-Trichloroethylene & & $150 \mathrm{~g} / 1$ \\
\hline Anodizing parameters: & $150 \mathrm{~g} / 1$ & $30 \pm 2^{\circ} \mathrm{C}\left(86 \pm 4^{\circ} \mathrm{F}\right)$ \\
Bath concentration & $30 \pm 2^{\circ} \mathrm{C}\left(86 \pm 4^{\circ} \mathrm{F}\right)$ & $16 \mathrm{ASF}$ \\
Bath temperature & $10 \mathrm{ASF}$ & $60 \pm 2 \mathrm{~min}$ \\
Current density & $45 \pm 2 \mathrm{~min}$ & \\
Anodize time & $\mathrm{N} / \mathrm{A}^{*}$ & $200 \mathrm{~g} / 1$ \\
\hline Cobalt acetate (dye Step 1) parameters: & & $6.0 \pm 0.1$ \\
Cobalt acetate concentration & & $45 \pm 3^{\circ} \mathrm{C}\left(110 \pm 5^{\circ} \mathrm{F}\right)$ \\
pH (acetic acid used to balance pH) & & $15 \mathrm{~min}$ \\
Temperature & $\mathrm{N} / \mathrm{A}^{*}$ & $30 \mathrm{~g} / 1$ \\
Time & & $24 \pm 3^{\circ} \mathrm{C}\left(75 \pm 5^{\circ} \mathrm{F}\right)$ \\
\hline Ammonium sulfide (dye Step 2) parameters: & $10 \mathrm{~min}$ \\
Ammonium sulfide concentration & & \\
Temperature & & $95^{\circ} \mathrm{C}\left(205^{\circ} \mathrm{F}\right)$ \\
Time & $100^{\circ} \mathrm{C}\left(212^{\circ} \mathrm{F}\right)$ & $5 \mathrm{~min}$ \\
\hline Hot water seal parameters: & $20 \mathrm{~min}$ & \\
Temperature & & \\
Immersion time & & \\
\hline
\end{tabular}

$* \mathrm{~N} / \mathrm{A}=$ Not applicable

Early results from analysis of other EOIM-3 specimens revealed the presence of a layer of silicone oxide approximately $20 \AA$ thick on AO-stable materials. ${ }^{8}$ It is believed that the contamination was caused by outgassing of an unidentified material.

\section{ANALYSIS}

\section{Lubricant Tests}

Table 4 summarizes the analyses conducted on each lubricant sample. Scanning Electron Microscopy (SEM) studies at 50 to $5000 \times$ magnification were conducted on control and post-flight solid film lubricant samples using the International Scientific Instruments Model DS 130S Dual Stage SEM. Energy dispersion X-ray analysis (EDX) was performed on discrete portions of the samples to determine differences in inorganic materials on the unexposed and exposed surfaces. Fourier transform infrared spectroscopy (FTIR) analysis, using a Nicolet Magna 550 FTIR spectrometer and a Nic-Plan microscope, was conducted on selected specimens in an effort to gauge the amount of binder erosion experienced. This was accomplished by comparing the height of the carbon-hydrogen bands and the energy peaks of the binder materials on the unexposed and exposed areas of each sample. Electron Spectroscopy for Chemical Analysis (ESCA) was performed at the NASA-JSC White Sands Test Facility on selected samples using a Perkin-Elmer PHI 5600 ESCA/Auger instrument and calibrated using a set of copper, silver, and gold standards for binding energy and etching rates. Concentrations of compounds were determined using the peak areas of the elements in energy states of interest from high resolution spectra plots. Also using the Perkin-Elmer PHI 5600 instrument, a depth profile was obtained to determine the depth of the oxygen- 
Table 4. Analyses Performed on Each Sample

\begin{tabular}{c|c|c|c}
\hline Lubricant & Passive tray & $\mathbf{6 0}^{\circ} \mathbf{C}$ tray & $\mathbf{1 2 0}^{\circ} \mathbf{C}$ tray \\
\hline \multirow{3}{*}{1} & SEM & SEM & SEM \\
& EDX & EDX & EDX \\
& FTIR & FTIR & FTIR \\
& ESCA & ESCA & ESCA \\
\hline \multirow{2}{*}{2} & & & SEM \\
& - & - & EDX \\
& & SEM & FTIR \\
\hline \multirow{3}{*}{3} & SEM & EDX & EDX \\
& EDX & FTIR & FTIR \\
\hline \multirow{3}{*}{4} & FTIR & SEM & SEM \\
& SEM & EDX & EDX \\
& EDX & FTIR & FTIR \\
& FTIR & ESCA & ESCA \\
\hline \multirow{2}{*}{5} & ESCA & SEM & SEM \\
\hline
\end{tabular}

affected layer using argon gas ions accelerated to $4 \mathrm{keV}$ and scanned on the surface. At discrete intervals, etching was suspended and an analysis of the surface was conducted. Etch rates were developed by comparing etch time with the time required to etch through a $1000 \AA$ thick layer of $\mathrm{Ta}_{2} \mathrm{O}_{5}$ on tantalum foil. Because the etch rates of the lubricants could not be guaranteed to be similar to the $\mathrm{Ta}_{2} \mathrm{O}_{5}$ etch rates, etch depth is expressed as a factor of the etch depth on the lubricant control samples.

\section{Anodic Coating Tests}

The control, pre-flight, and post-flight anodic coating samples were measured for solar absorptance using the Gier-Dunkle Model MS251 Solar Reflectometer (referred to in this report as the MS251), and for infrared emittance using the Gier-Dunkle Model DB100 Infrared Reflectometer (referred to in this report as the DB 100). The MS251 uses a xenon lamp with a 100-mm diameter integrating sphere and measures solar reflectance in a wavelength range of approximately 300 to $2000 \mathrm{~nm}$. The DB100 uses a rotating heated cavity with a hard black anodize coating which can measure infrared reflectance from 5 to $14 \mu \mathrm{m}$.

The control, pre-flight, and post-flight clear SAA samples and the control and post-flight cobalt sulfide dyed SAA samples were also measured for solar absorptance using the Perkin-Elmer Lambda 9 spectrophotometer (referred to in this report as the Lambda 9). The Lambda 9 uses tungsten and deuterium lamps with a $150-\mathrm{mm}$ diameter integrating sphere and measures solar reflectance in a wavelength range of 250 to $2500 \mathrm{~nm}$. Data from the Lambda 9 are analyzed using a technique to account for wavelengths smaller than $250 \mathrm{~nm}$ and larger than $2500 \mathrm{~nm}$. The final result is expected to yield values closer to the "true" solar reflectance than the MS251.

Surface morphology and chemistry of control and post- flight samples were studied using SEM and EDX similar to that used for the lubricant samples. 


\title{
RESULTS
}

\author{
Results of Lubricant Specimens
}

\section{Lubricant 1}

Comparison of the SEM photographs of the exposed and unexposed surfaces of the passive tray sample (Figure 1) shows a "worm-eaten" preferential erosion of particular materials that is typical of the exposed material on all three tray samples. EDX analysis revealed no gross difference between materials in the eroded and non-eroded areas. EDX indicated that the eroded material was $\mathrm{MoS}_{2}$, but because the EDX was conducted at a high power, the analysis may have detected the material lying underneath the eroded material. Erosion appears to be slightly more extensive in the passive tray sample than in the heated tray samples (Figure $1 \mathrm{~b}$ and Figure 2).

There is a transition zone between the unexposed and the exposed areas on the two heated samples, which is evidenced by a light region on the SEM photographs. EDX analysis of these areas indicates a higher level of aluminum than in other areas, suggesting the lubricant had been rubbed off either by the sample carrier or by other means. Otherwise, there is little discemible difference between the three specimens.

FTIR plots of the exposed and unexposed areas of the samples were too noisy to determine any significant difference.

ESCA detected trace amounts (under $40 \AA$ ) of silicone and fluorine on the samples. ESCA detected $\mathrm{MoO}_{3}$ only on the sample on the $120^{\circ} \mathrm{C}$ tray. The presence of $\mathrm{MoO}_{3}$ on the other tray samples may have been masked by $\mathrm{MoS}_{2}$ peaks, which are situated close to the $\mathrm{MoO}_{3}$ peaks. On the surface of the $120^{\circ} \mathrm{SDC}$ sample, $30 \%$ to $50 \%$ of the molybdenum detected was in the form of $\mathrm{MoO}_{3}$. Analysis of $\mathrm{MoO}_{2}$ using this technique was inconclusive because the oxygen present in the binder masked the $\mathrm{MoO}_{2}$ peaks. The depth of the oxygen-affected layer was estimated to be the depth at which the oxygen concentration remained

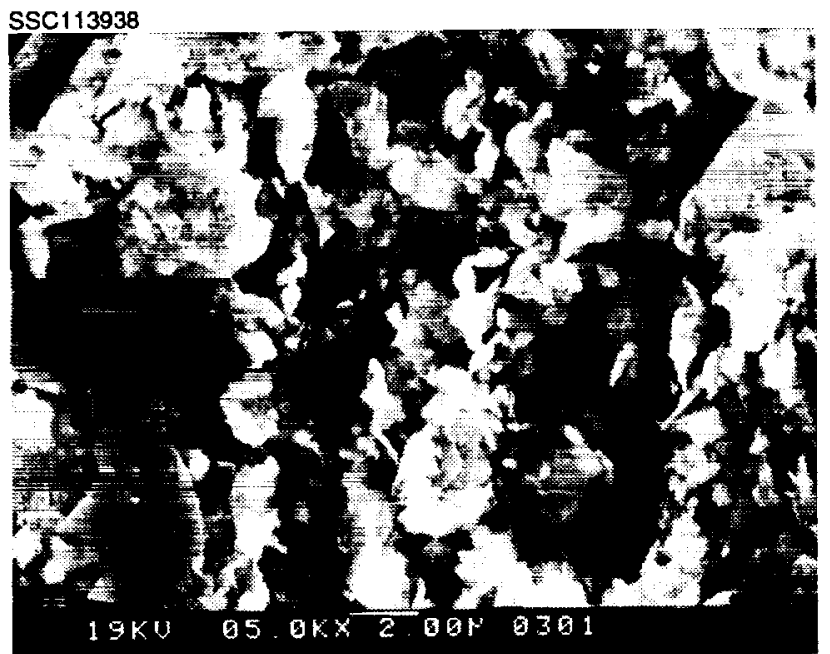

a. Unexposed Surface

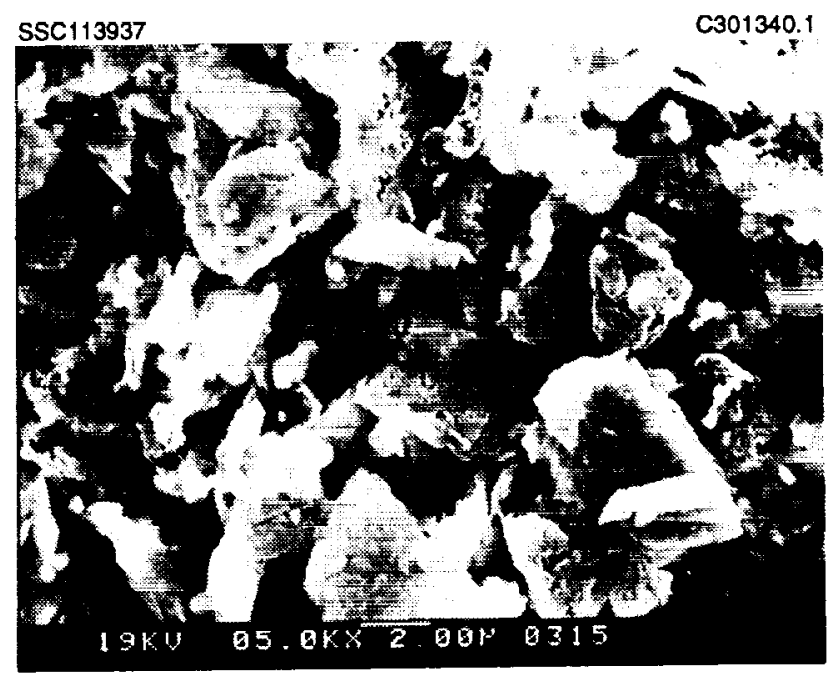

b. Exposed Surface

Figure 1. SEM photographs of lubricant 1 passive tray sample. 


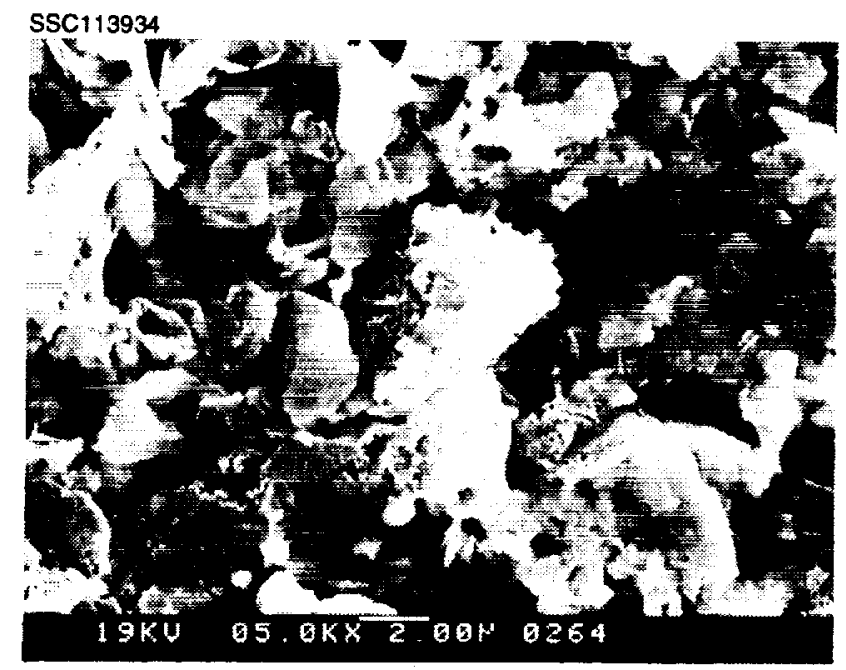

a. Exposed Surface on $60^{\circ} \mathrm{C}$ Tray

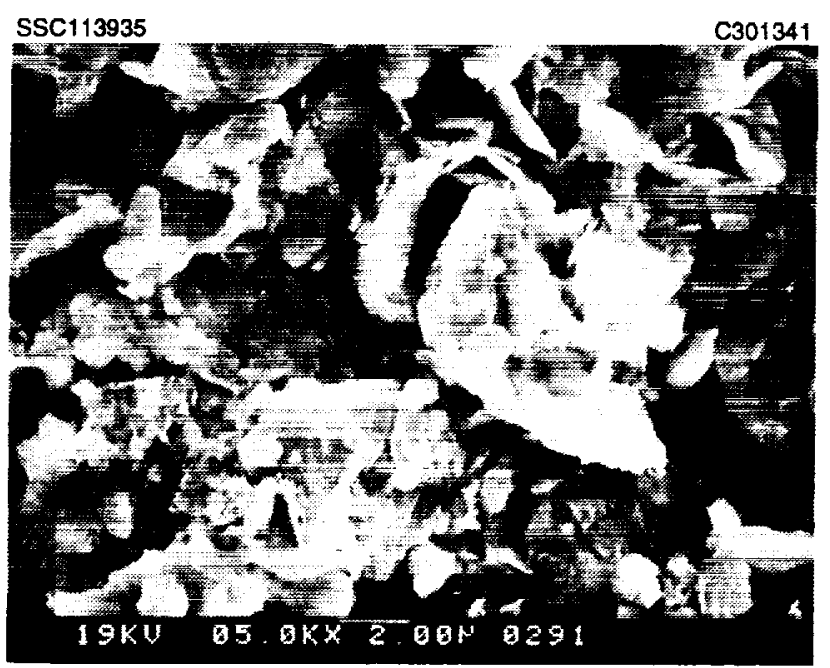

b. Exposed Surface on $120^{\circ} \mathrm{C}$ Tray

Figure 2. Lubricant 1 exposed surfaces on heated trays.

more than $50 \%$ of the difference between the maximum oxygen concentration and the background oxygen concentration. Table 5 contains the results of the depth analysis. The $120^{\circ} \mathrm{C}$ sample had the thickest oxygen layer.

Table 5. Oxygen-Affected Layer Thickness for Lubricant 1

\begin{tabular}{c|c}
\hline Sample location & Depth of oxygen-affected layer* \\
\hline Passive Tray & $4.5-5.0$ \\
\hline $60^{\circ} \mathrm{C}$ Tray & $6.8-7.5$ \\
\hline $120^{\circ} \mathrm{C}$ Tray & $7.0-8.0$ \\
\hline
\end{tabular}

* Expressed as a multiple of control sample oxygen layer depth.

\section{Lubricant 2}

The only specimen of this lubricant was on the $120^{\circ} \mathrm{C}$ tray. The specimen had a screen installed over it. In the SEM photo (Figure 3), the exposed areas are distinctly lighter in shade than the unexposed areas. SEM photos also show a semitransparent material, presumably the polyimide binder, on the unexposed surfaces (Figure 4). The exposed samples appear to be missing this material. EDX analysis indicates no discernible difference in materials present in the unexposed and exposed areas.

FTIR analysis of the exposed and unexposed surfaces indicated no difference in binder concentration.

\section{Lubricant 3}

There is no discernible difference between the three tray samples in the SEM photographs. On all the samples, the exposed area is lighter than the unexposed area on all samples (Figure 5). There is a semitransparent material, assumed to be the phenolic binder, on the unexposed surfaces. The exposed surfaces lack this material (Figure 6). EDX analysis shows very little difference between the materials in the exposed and unexposed areas, and very little difference between the samples themselves. 


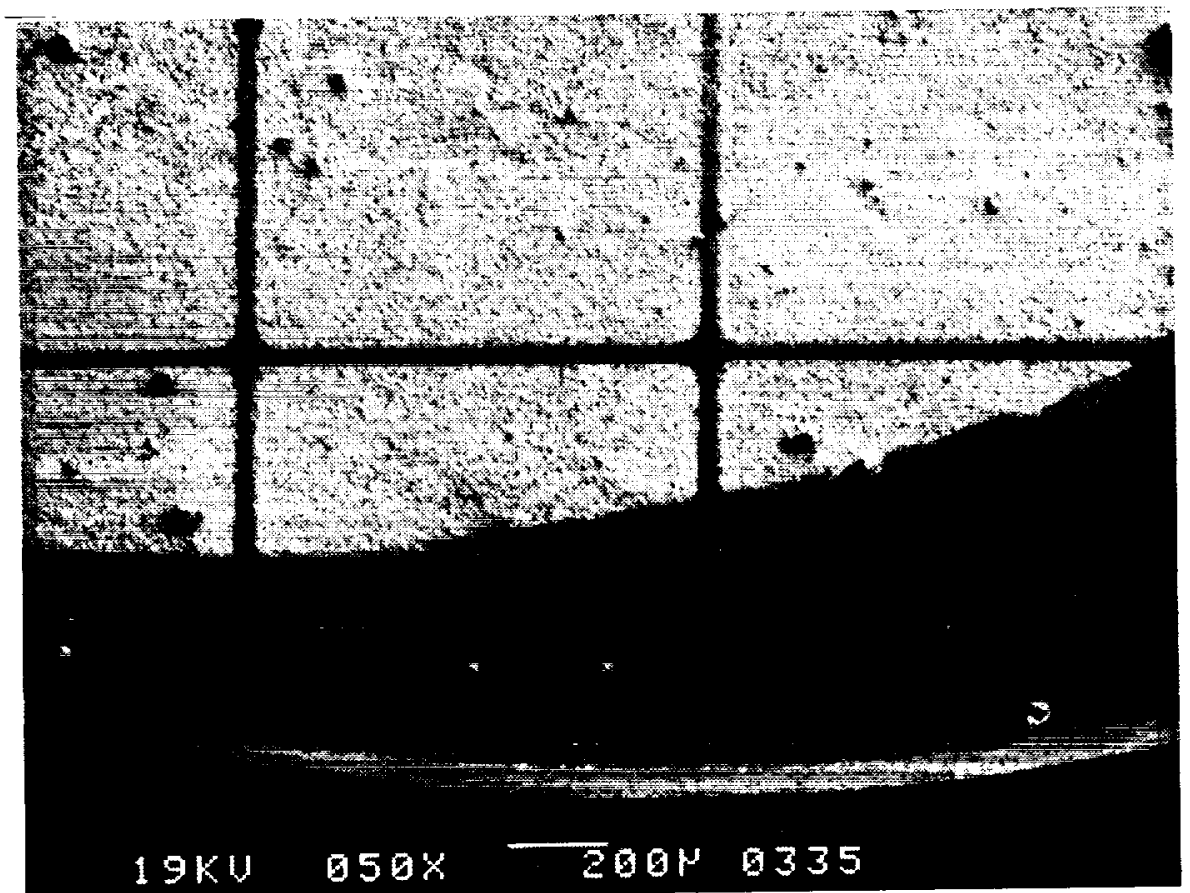

Figure 3. SEM photograph of unexposed, exposed surface of lubricant 2.

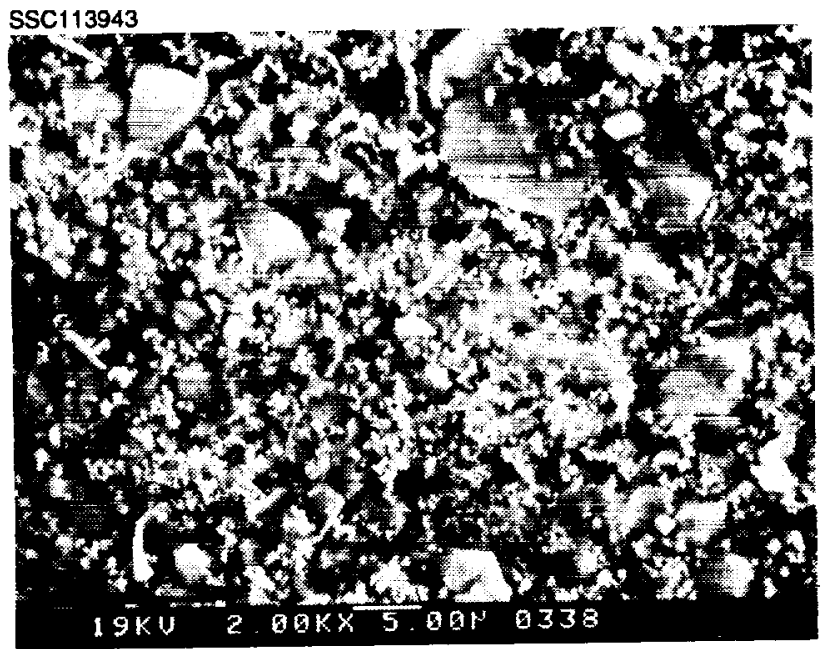

a. Unexposed Surface

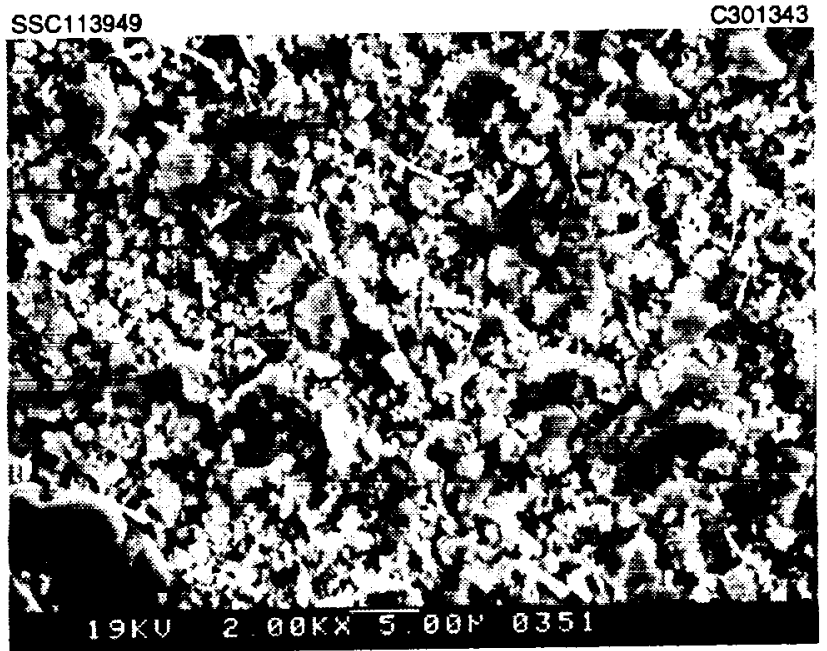

b. Exposed Surface

Figure 4. SEM photograph of lubricant 2.

FTIR analysis of the surfaces of each specimen indicates no distinguishable binder on the exposed surface of the $120^{\circ} \mathrm{C}$ specimen, slight indication of binder on the exposed surface of the $60^{\circ} \mathrm{C}$ specimen, and a stronger indication on the exposed surface of the passive sample (Figure 7).

\section{Lubricant 4}

There is no discernible difference between the three specimens in the SEM photographs. The exposed area is lighter than the unexposed area on all samples. There is a semitransparent material, assumed to be the phenolic binder, on the unexposed surfaces (Figure 8a). The exposed areas appear to have some binder left (Figure 8b). The binder that is left does not exhibit the preferential erosion observed on the Lubricant 1 samples. Rather, the exposed binder appears receded, indicating a uniform erosion of material. EDX of 


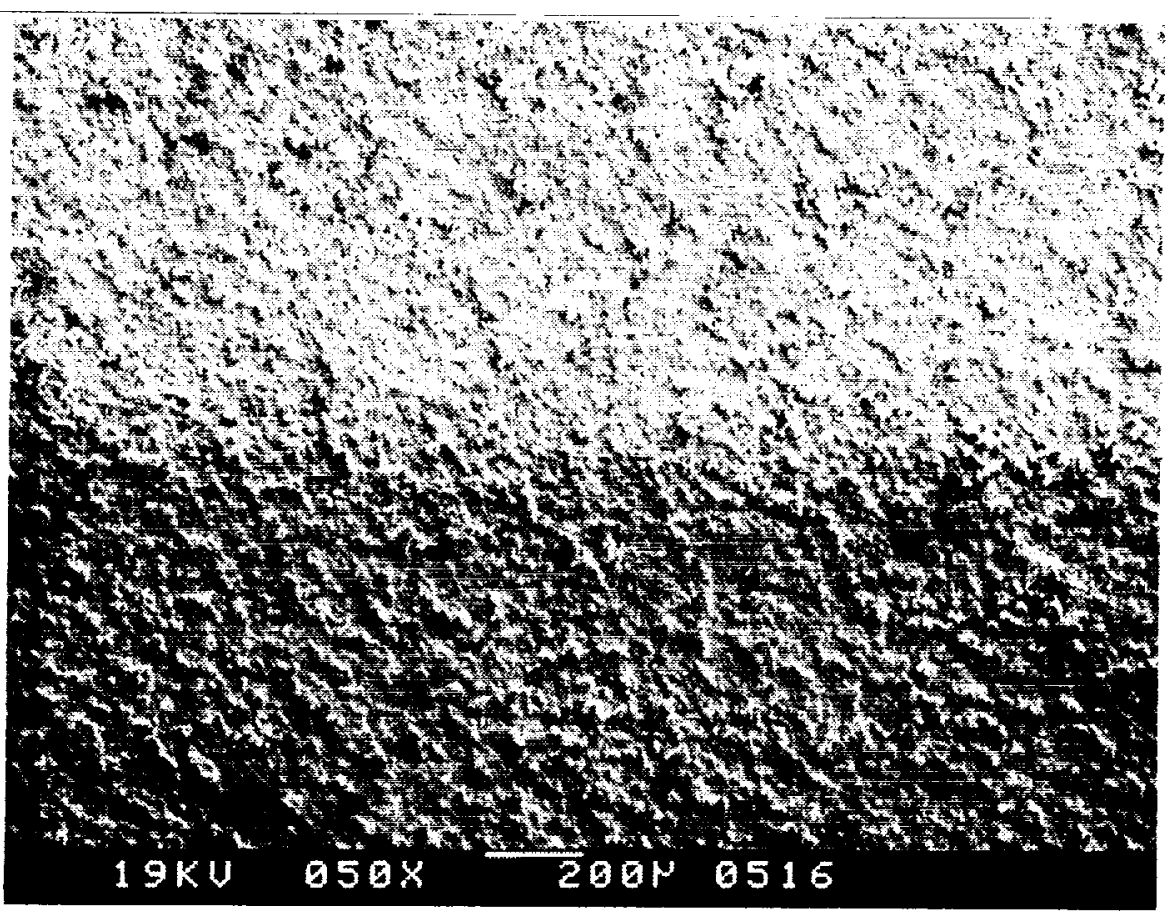

Figure 5. SEM photograph of transition from unexposed to exposed area on lubricant $360^{\circ} \mathrm{C}$ sample.

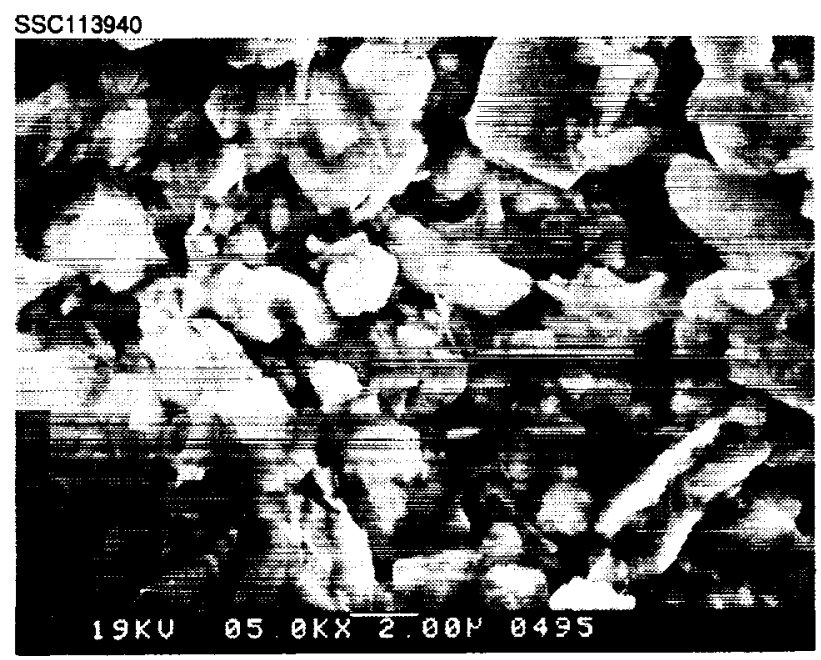

a. Unexposed Surface

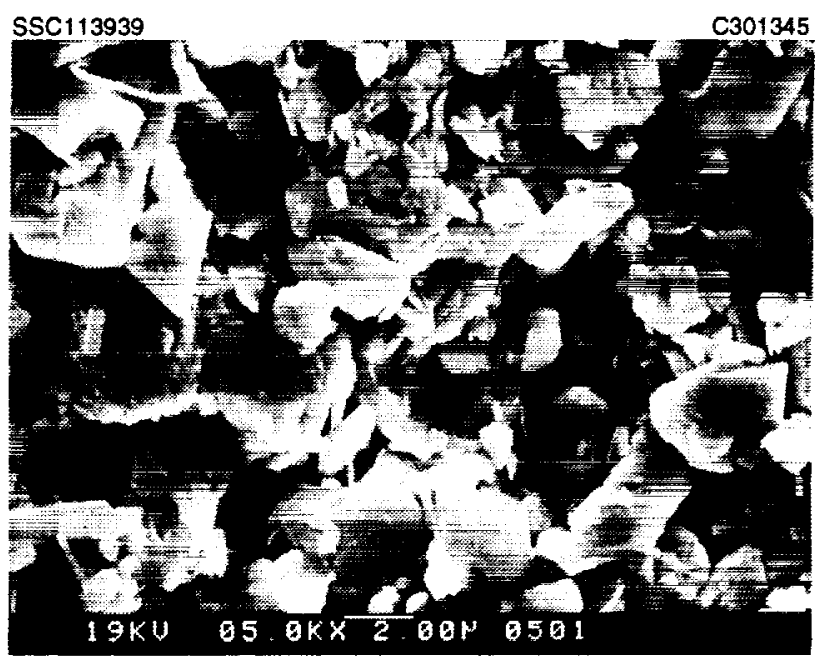

b. Exposed Surface

Figure 6. SEM photographs of unexposed, exposed surfaces of lubricant 3 passive tray sample.

exposed and unexposed areas are virtually identical, and comparison of the three samples reveal no substantive difference. FTIR did not detect a significant difference in binder concentration from unexposed to exposed areas on the samples.

ESCA revealed trace amounts of silicone and fluorine on the samples. $\mathrm{MoO}_{3}$ was detected on all three samples. Table 6 shows the estimated amounts of $\mathrm{MoO}_{3}$ (as a percentage of the molybdenum detected) and the depth of the oxygen-affected layer. The highest concentration of $\mathrm{MoO}_{3}$ was found on the passive sample, followed by the $60^{\circ} \mathrm{C}$ and $120^{\circ} \mathrm{C}$ samples, but the thickest oxygen layer was found on the $120^{\circ} \mathrm{C}$ sample. 


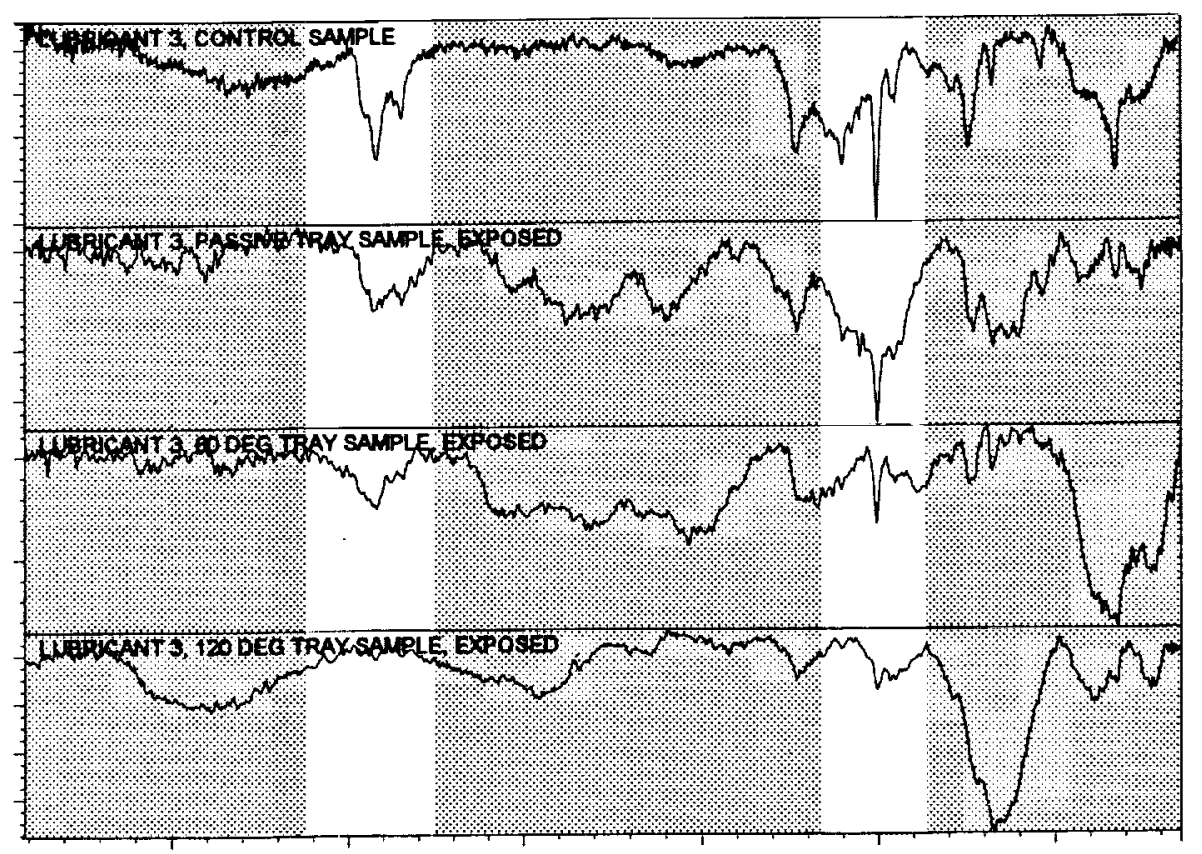

Figure 7. FTIR plots of lubricant 3 samples with phenolic peaks highlighted.

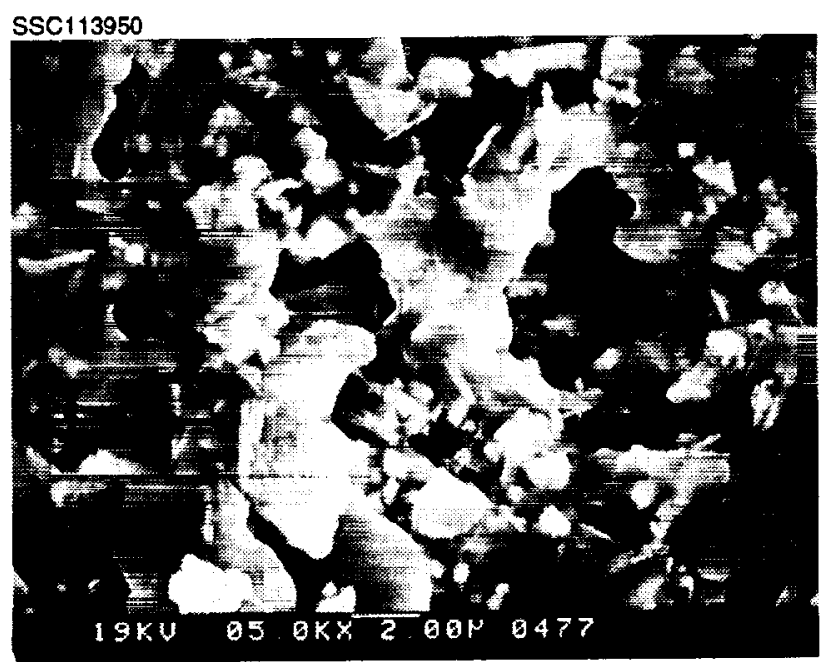

a. Unexposed Surface

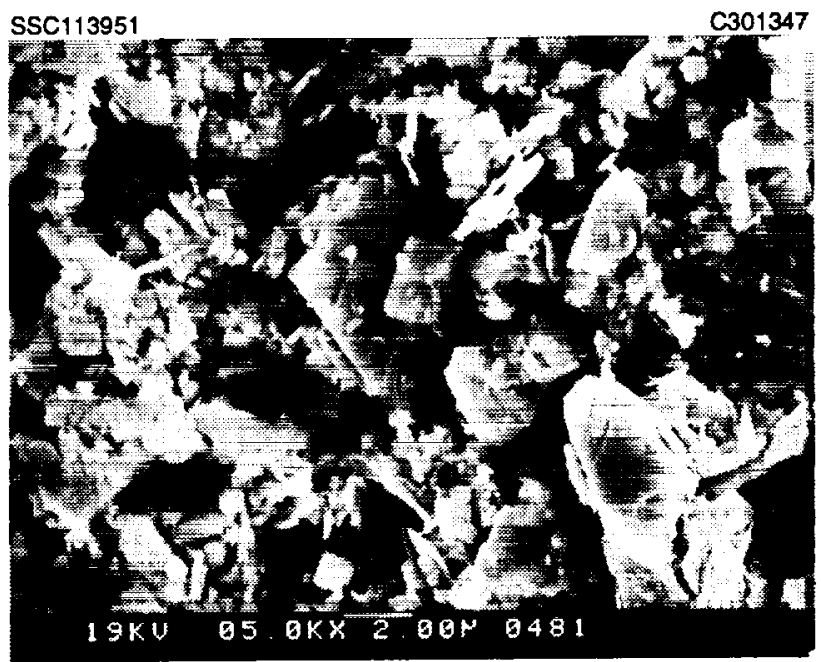

b. Exposed Surface

Figure 8. SEM photographs of unexposed, exposed surfaces of lubricant $460^{\circ} \mathrm{C}$ tray sample.

Table 6. Oxygen Affected Layer Thickness for Lubricant 4

\begin{tabular}{c|c|c}
\hline Sample hocation & Depth of oxygen-affected layer * & MoO3/Mo (\%) \\
\hline Passive & $5.0-7.0$ & $56-76$ \\
\hline $60^{\circ} \mathrm{C}$ & $4.8-7.4$ & $38-58$ \\
\hline $120^{\circ} \mathrm{C}$ & $5.6-8.6$ & $30-50$ \\
\hline
\end{tabular}

${ }^{*}$ Expressed as a multiple of control sample oxygen layer depth. 


\section{Lubricant 5}

There is little discernible difference between the unexposed and exposed areas of any of the samples in the SEM photographs. Each sample had bright, gray, and dark shaded regions on the SEM photographs (Figure 9). The gray areas fill in between thin, long, dark features. White features are randomly scattered. EDX analysis indicates that the bright and dark shades have high levels of aluminum, while the gray areas are high in tungsten and sulfur, leading to the conclusion that the gray areas are the air-impinged tungsten disulfide solid film lubricant. Stereo photographs indicate that the dark aluminum areas are physically lower than the lubricant.

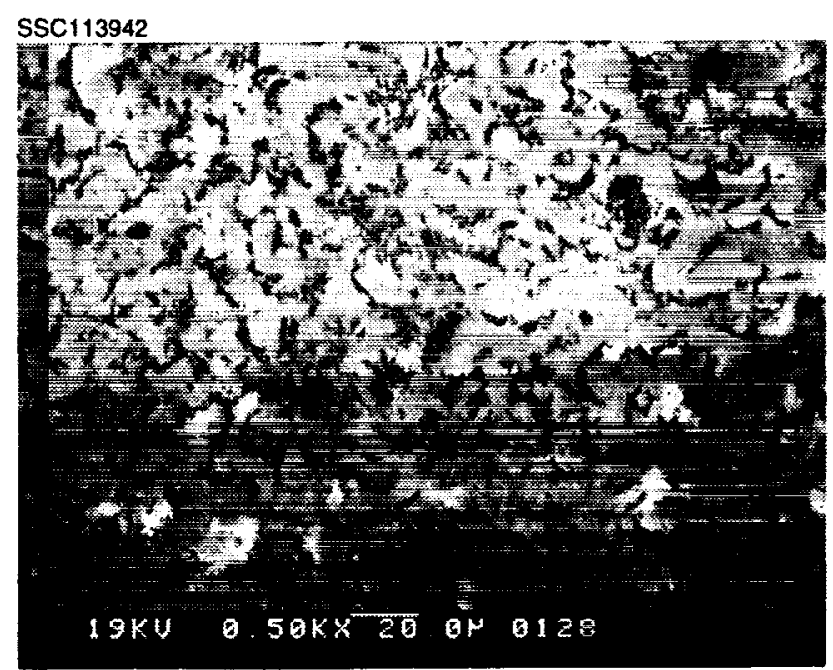

a. Unexposed Surface

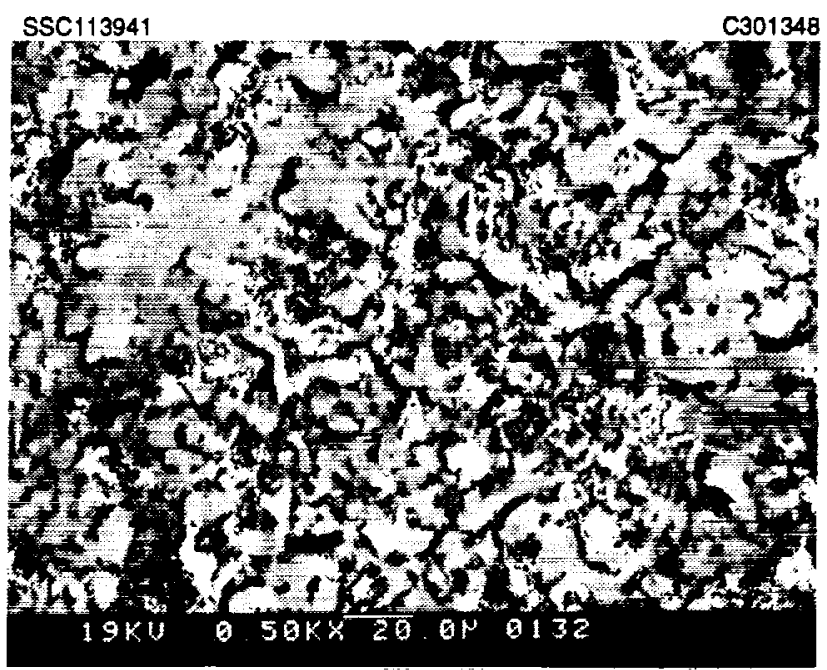

b. Exposed Surface

Figure 9. SEM photographs of unexposed, exposed surfaces of lubricant 4.

The passive sample had a screen placed over it. The shadow of the screen is barely visible (Figure 10). The $60^{\circ} \mathrm{C}$ specimen had the strongest shade contrast between the darker unexposed area and the lighter, exposed area. The areas are separated by a bright transition band (Figure 11). X-ray mapping of the transition indicates that neither an abundance nor a dearth of aluminum or tungsten is responsible for the transition.

\section{Discussion of Lubricant Analyses}

All the lubricants with binders experienced some form of erosion from exposure. The data did not indicate that temperature consistently influenced the amount of erosion experienced. SEM photographs revealed preferential erosion on discrete features on the inorganic binder lubricant, while the organic binder lubricants exhibited an even, recession-type erosion of the binder. The inorganic and organic binder lubricants had oxygen-affected layers of similar thickness. Surface $\mathrm{MoO}_{3}$ concentrations on the inorganic and organic binder lubricants were similar to each other and to the concentrations detected on the simulated LEO-exposed sputtered $\mathrm{MoS}_{2}$, even though the laboratory AO energy was lower and fluence higher than the EOIM- 3 exposure ( $1.5 \mathrm{eV}$ and $5 \times 10^{24}$ atoms $/ \mathrm{cm}^{2}$ compared with $5 \mathrm{eV}$ and $2 \times 10^{20}$ atoms/ $\mathrm{cm}^{2}$, respectively). 


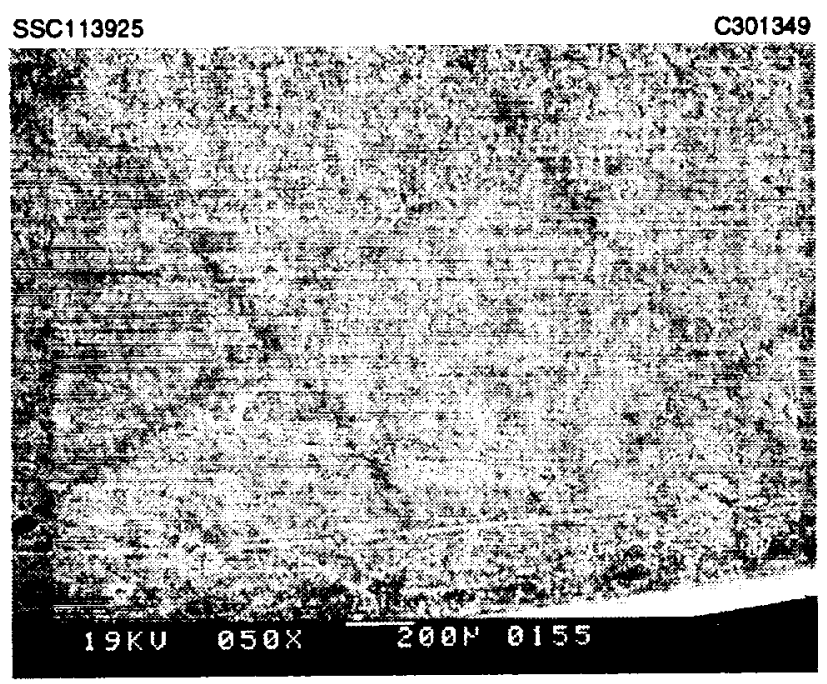

Figure 10. SEM photograph of lubricant with shadow from mesh screen.

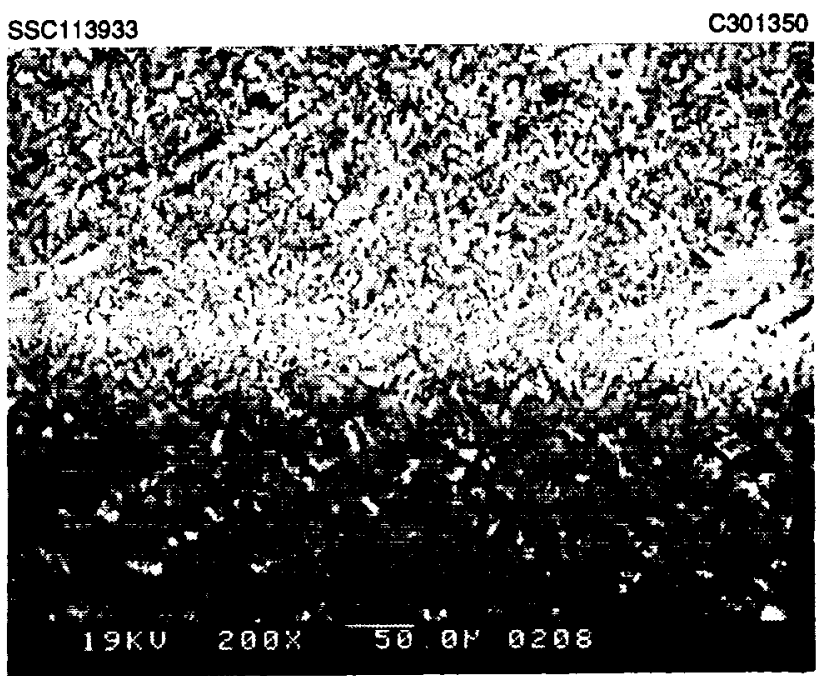

Figure 11. SEM photograph of transition from unexposed to exposed surfaces of lubricant 5.

\section{Results of Anodic Coating Studies}

The post-flight optical property results for the anodic coatings are shown in Table 7. After 42 hours of exposure in the LEO environment, the non-dyed SAA on 7075-T73 showed very little change in absorptance. The increase in absorptance of 0.01 is within the error of the measurement device. The increase in absorptance for the 2219-T851 sample $(\Delta \alpha=0.03)$, which is slightly more significant, can be attributed to UV degradation and contamination. UV degradation of anodic coatings is generally logarithmic with most of the degradation occurring in the first 200 hours. ${ }^{3}$ When the degradation is attributed solely to UV degradation, and a logarithmic degradation is assumed, the 30-year predicted degradation is below 0.10 . This is well within the 30 -year absorptance degradation of 0.20 that was predicted for this coating. ${ }^{3}$ The effect appeared to be confined to the wavelength range below $850 \mathrm{~nm}$. Lambda 9 reflectance spectrums for the pre-flight and post-flight measurements are shown in Figure 12. The confinement of absorptance effects to this narrow wavelength range may be attributed to the presence of silicone, which was detected in a 4-keV beam energy EDX study of the 2219-T851 flight sample. In addition, the affected wavelength range includes wavelengths at which the incident energy from the sun has the highest potential to induce rupture of chemical bonds. ${ }^{9}$ It is not clear from the data available why the 2219 substrate degraded more than the 7075 substrate.

Table 7. Post-Flight Optical Property Changes

\begin{tabular}{c|c|c|c}
\hline Coating & Substrate & $\Delta \alpha$ & $\Delta \varepsilon$ \\
\hline Clear SAA & $2219-\mathrm{T} 851$ & $0.03^{\mathrm{a}}$ & 0.00 \\
\hline Clear SAA & $7075-\mathrm{T} 73$ & $0.01^{\mathrm{a}}$ & 0.00 \\
\hline CoS Dyed SAA & $6061-\mathrm{T} 6$ & $-0.20^{\mathrm{b}}$ & 0.00 \\
\hline CoS Dyed SAA & $7075-\mathrm{T} 73$ & $0.08^{\mathrm{b}}$ & 0.00 \\
\hline
\end{tabular}

Notes: Einittances measured using the Gier-Dunkle DB100. Differences in absorptance or emittance of less than 0.02 are not considered significant.

a. Absorptances measured using the Lambda 9.

b. Absorrtances measured using the MS251. 


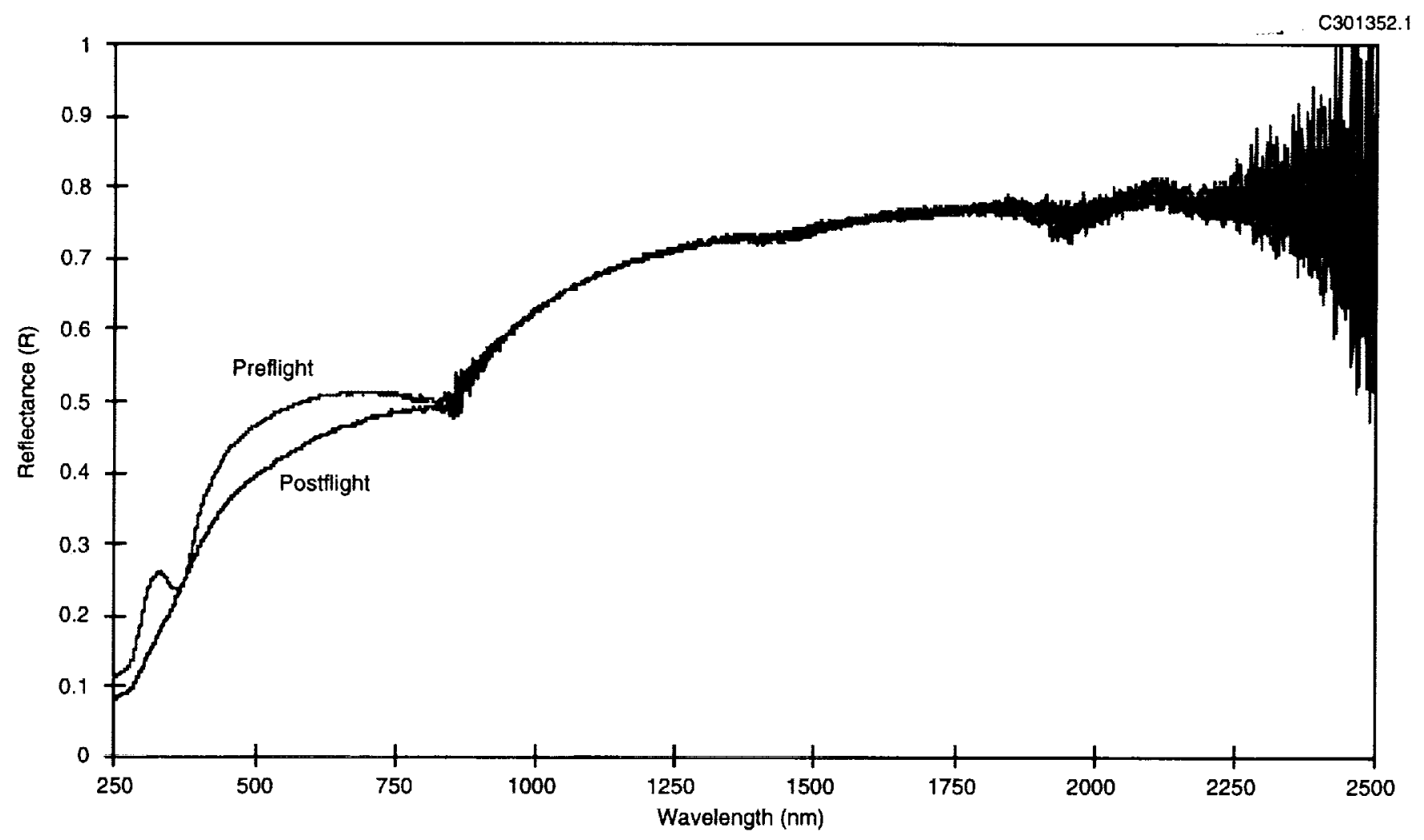

Figure 12. Pre- and postflight solar reflectance spectra for non-dyed sulfuric acid anodized 2219-T851 aluminum.

Because of the lack of available manufacturing facilities with production cobalt sulfide dye capability, environmental compliance issues, and concerns about optical property consistency, the cobalt sulfide dyed SAA process is no longer baselined for MDA Space Station hardware. However, EOIM-3 data are useful in evaluating cobalt sulfide as a potential backup coating.

Both the black cobalt-sulfide dyed SAA samples showed changes in absorptance. The cobalt-sulfide dyed SAA on 6061-T6 aluminum appeared to fade dramatically, and the absorptance was reduced by about 0.20 . This effect is attributed to AO removal of the dye, which was confirmed when ground asher AO exposures of the EOIM-3 ground control samples at MDA exhibited similar fading. The results of the asher test are shown in Table 8. The asher was run at a vacuum of 2 torr and a power of $100 \mathrm{~W}$ and reached a maximum temperature of $57^{\circ} \mathrm{C}\left(135^{\circ} \mathrm{F}\right)$ during the run. The total fluence of the test was approximately $2.8 \times 10^{21}$ atoms $/ \mathrm{cm}^{2}$, as calculated using Kapton $\mathrm{HN}$ polyimide standards. The test exposure was nearly ten times that experienced by EOIM-3 samples.

The results of ground AO exposure of the CoS dyed 6061-T6 are similar to those observed on orbit. The similarity suggests that the temperature of the sample and the velocity and directionality of the AO did not influence the removal rates. The bleaching effect on the 6061-T6 substrate observed on both ground exposed and flight exposed samples may be attributable to $\mathrm{AO}$ removal of the dye and is unexpected because the dye is inorganic. Because the CoS dyed 6061-T6 was a recent alloy addition to the Space Station program, CoS dyed 6061-T6 was not subjected to AO testing at MDA prior to the EOIM-3 flight. However, other alloys with $\mathrm{CoS}$ dye were not similarly affected by AO testing. A possible $\mathrm{pH}$ imbalance in the first dye bath during processing of the flight 6061-T6 samples may have contributed to the bleaching. Testing of additional samples is necessary to confirm AO bleaching of the cobalt sulfide dye on the 6061-T6 substrate. 
The cobalt-sulfide dyed SAA on 7075-T73 aluminum did not fade during flight exposure, but acquired a slight yellowish sheen, which was not observed on the ground AO sample. The absorptance increased by 0.08 . The yellowish sheen on the 7075-T73 sample and the increase in absorptance may have been caused by contamination. This explanation is supported by the ground AO sample exhibiting an increase of only 0.03 . The contamination appeared to have a greater effect on cobalt sulfide dyed SAA on 7075-T73 than it had on the non-dyed SAA on 2219-T851 or 7075-T73.

\section{SUMMARY}

Analysis of solid film lubricants exposed to LEO on EOIM-3 revealed effects similar to those observed in laboratory simulated environment tests on sputtered $\mathrm{MoS}_{2}$. On organic binder lubricants, the binders were eroded evenly, while on inorganic binder lubricants, preferential attack was evident. The unbonded lubricant did not exhibit erosion per se, but SEM photographs show the exposed surfaces to be lighter in shade, much like the exposed surfaces on the other lubricants. $\mathrm{MoO}_{3}$ was detected on the inorganic and organic binder lubricants analyzed by ESCA. Concentrations were of the same magnitude of those detected on sputtered $\mathrm{MoS}_{2}$ specimens exposed to simulated AO.

The non-dyed sulfuric acid anodic coatings flown on the MDA EOIM-3 sub-experiment behaved as expected when exposed to the LEO environment. Degradation did not occur with SAA on the 7075-T73 substrate. With the 2219-T851 substrate, minimal increases in absorptance were found. The environmental resistance of the cobalt sulfide dyed sulfuric acid anodic coatings may be dependent on the dye process or the substrate. CoS-dyed SAA on 6061-T6 was severely bleached by AO, while CoS-dyed SAA on 7075T73 was not bleached by AO exposure, but it experienced a significant increase in absorptance. On 7075T73, the black CoS-dyed SAA coating appeared to be more susceptible to absorptance increases due to contamination than the non-dyed SAA coating. EOIM-3 data indicate that $\operatorname{CoS}$ dyed SAA may not be stable in LEO and would not be suitable for applications where stable optical properties are required. It is no longer viewed as a backup high absorptance anodize coating. Non-dyed sulfuric acid anodize, as produced for MDA Space Station hardware, appears to be resistant to the low Earth orbit environment.

Opportunities to test the effects of LEO exposure on the tribological properties of solid film lubricants are being pursued. The clear SAA process will be tested for LEO effects on the other aluminum alloys being used on Space Station; the baseline high-absorptance anodize coating is also being tested for LEO effects.

\section{ACKNOWLEDGMENTS}

The authors wish to thank Huong Le, Vic Kerlins, Alan Babrocky, Charles Smith, and Carl Oda, of MDA-Huntington Beach, for their assistance in the measurement and interpretation of the data. Dr. Steve Hornung of NASA White Sands Test Facility provided superior support in the analysis of the lubricant samples. 


\section{REFERENCES}

1. L.J. Leger, J.T. Visentine, and J.A. Schlieseng, "A Consideration of Atomic Oxygen Interaction with Space Station." AIAA Paper 85-0476, AIAA 23rd Aerospace Sciences Meeting, Reno, Nevada, 14-17 January 1985.

2. J.A. Martin, et al., "MoS 2 Interactions with $1.5 \mathrm{eV}$ Atomic Oxygen." Materials Research Society, 1988 Fall Meeting, Boston, Massachusetts, 28 November-3 December 1988, Los Alamos National Laboratory document LA-UR-88-1977.

3. K.E. David and H.W. Babel, "Optical Property Degradation of Anodic Coatings in the Space Station Low Earth Orbit. " Presented at the AIAA Materials Specialist Conference, Dallas, Texas, 16-17 April 1992.

4. C.A. Jones, et al., "Environmental Effects on Passive Thermal Control Materials on the Space Station Freedom." Presented at the 44th Congress of the International Astronautical Federation, Graz, Austria, 16-22 October 1993.

5. D. Duffy, Engineering Trade Study Report on Durable/Long-Life Radiator Coatings, for NASA Lyndon B. Johnson Space Center, NAS9-17530, November 1987.

6. J.H. Weaver, "Effects of Vacuum-Ultraviolet Environment on Optical Properties of Bright Anodized Temperature Control Coatings." Air Force Materials Laboratory Technical Report, AFML-TR-67-421, May 1968.

7. W.R. Wade and D.J. Progar, "Effects of a Simulated Space Environment on Thermal Radiation Characteristics of Selected Black Coatings." NASA Technical Note, TN D-4116, September 1967.

8. D.E. Brinza, "Early Results From the JPL Experiments on the Evaluation of Oxygen Interactions with Materials (EOIM-3) Experiment Aboard STS-46." Presented at the EOIM-3 BMDO Flight Experiment Workshop, 22 June 1993.

9. S. Wernick, et al., The Surface Treatment and Finishing of Aluminum and Its Alloys-5th ed. Vol 2, 1987 (Finishing Publications Ltd: Teddington, Middlesex, England). 